\title{
Characteristics Associated with Disclosure Status to Sexual Partners among Kenyan Women
}

\author{
Haley Greene ${ }^{1}$, Pauline E Jolly ${ }^{1, *}$, Tierra Johnson ${ }^{1}$, Ruby Galarza ${ }^{1}$, Walter Jaoko ${ }^{2}$ and Luz A Padilla ${ }^{1}$ \\ ${ }^{1}$ Department of Epidemiology, Ryals School of Public Health, University of Alabama at Birmingham, Alabama, USA \\ ${ }^{2}$ Department of Medical Microbiology, University of Nairobi, Nairobi, Kenya
}

*Corresponding author: Pauline E Jolly, Department of Epidemiology, Ryals School of Public Health, University of Alabama at Birmingham, Alabama, USA, Tel: (205) 974-1823; E-mail: jollyp@uab.edu

Received: 25 Jul, 2019 | Accepted: 31 Aug, 2019 | Published: 06 Sep, 2019

Citation: Greene H, Jolly PE, Johnson T, Galarza R, Jaoko W, et al. (2019) Characteristics Associated with Disclosure Status to Sexual Partners among Kenyan Women. J HIV AIDS 5(2): dx.doi.org/10.16966/2380-5536.166

Copyright: (c) 2019 Greene H, et al. This is an open-access article distributed under the terms of the Creative Commons Attribution License, which permits unrestricted use, distribution, and reproduction in any medium, provided the original author and source are credited.

\section{Abstract}

Background: Kenya has the fourth-largest HIV epidemic across the globe. Disclosure of HIV-positive status plays a critical role in the prevention of HIV transmission. Disclosure, specifically to sexual partners, has been shown to foster safer sexual behaviors in addition to emotional, social, or monetary support from partners.

Objective: This study was conducted to identify factors associated with HIV-positive status disclosure to sexual partners compared to disclosure to other than sexual partners.

Methods: A cross-sectional study was conducted from May to August 2012 among 497 HIV-positive women 19-49 years of age who had sex in the past six months. Participants were recruited from the Kenyatta National Hospital and Mbagathi Direct Hospital in Nairobi, Kenya. A questionnaire was administered to obtain data on HIV disclosure. Bivariate and multivariable logistic regression analyses were conducted to identify factors associated with disclosure of HIV-positive status to sexual partners.

Results: Of the 497 women, 349 reported to whom they had disclosed their HIV status. Approximately $34 \%$ had disclosed their HIV-positive status to a sexual partner. Women who disclosed to their sexual partners were 11 times more likely to be married or in a common-law relationship and 4 times more likely for their sexual partner or spouse to be the heads of the households. Frequency of condom use, belief that HIV disclosure is important for HIV prevention and control, knowledge of partner's HIV status, and number of sex partners were also significantly associated with disclosing to a sexual partner.

Conclusion: This study found a low rate of disclosure of HIV-positive status by women to sexual partners and identified a number of factors associated with disclosure to sexual partners. These findings can be used in designing interventions that focus on individuals who have not disclosed their HIVpositive status to their sexual partners by demonstrating the importance of disclosure and safe sex practices.

Keywords: HIV/AIDS; HIV Disclosure; Women; Sexual Risk Behaviors; Kenya

\section{Introduction}

People living with HIV/AIDS (PLWHA) experience various barriers that may influence their decision to disclose their HIV status; for example, loss of social support, HIV-related discrimination, wish to protect oneself or others emotionally, concern about insurance or loss of employment, access to care and support services, or intimate partner violence [1,2]. The disclosure of HIV-positive status plays a critical role in the prevention of HIV transmission to others and the alleviation of its impact on quality of life, stigma, treatment understanding, and social support [2]. In order to manage the obstacles associated with HIV infection, disclosure of HIV-positive status specifically to sexual partners has been shown to create a relationship that fosters safer sexual behaviors in developing countries where women tend to be more dependent on their partners [3-5]. Disclosing one's HIV-positive status is also related to the prevention of HIV transmission as well as emotional, social, or monetary support from partners [3-5]. While the benefits of HIV disclosure are thought to outweigh the risks, HIV disclosure status remains low in many African countries, and stigma and lack of social support are often associated with nondisclosure [6].

The average rate of HIV disclosure in the developing world is notably less than the average rate reported from studies in industrialized countries with percentages between $42 \%$ to $100 \%$ [3,4,7-9]. Rates of HIV disclosure to sexual partners vary significantly with percentages between $16.7 \%$ to $86 \%$ of women choosing not to disclose their HIV-positive status to their sexual partners in Africa [3,4,7-9]. In 
southern Africa, approximately $42 \%$ of PLWHA have disclosed their HIV-positive status to a sexual partner, and roughly, $72 \%$ of those who have not disclosed have multiple partners [8]. Additionally, chiefly attributed to barriers to disclosure such as separation or loss of sole source of income, women in Uganda were most likely to disclose their HIV-positive status to their sisters (21\%) while men were most likely to disclose to their sexual partners (27\%); in fact, only $22 \%$ of Tanzanian women have disclosed their HIV-positive status to their sexual partner $[7,10]$.

Along with Mozambique and Uganda, Kenya holds the fourthlargest HIV epidemic across the globe [11]. The overall HIV prevalence was estimated at approximately $4.9 \%$ in 2017 with roughly 28,200 people dying from AIDS-related causes in Kenya that year [11]. The epidemic affects the general population and leaves groups of women who are African American, transgender, injection drug users, sex workers, or those with a low socioeconomic status more vulnerable to infection $[11,12]$. Compared to their male counterparts, young women are almost twice as likely to be infected with HIV in addition to having a higher prevalence of HIV when compared to men $(5.2 \%$ vs. $4.5 \%)[11,12]$. Research shows that women are less likely to disclose their HIV-positive status to their spouses, and the failure to disclose HIV-positive status to a sexual partner may influence the rates of HIV infection among the population [10]. This study sought to identify factors associated with HIV status disclosure by women to their sexual partners compared to women who disclosed to someone other than their sex partner.

\section{Materials and Methods}

\section{Study sites and participants}

In 2012, 497 clinically confirmed HIV-positive women receiving care in Nairobi, Kenya at Kenyatta National Hospital (KNH) or Mbagathi District Hospital (MDH) participated in this cross-sectional study. Kenyatta National Hospital is the largest hospital in the country; it has a 1,800-bed capacity and receives 89,000 admissions per year [13]. Mbagathi District Hospital is a smaller hospital that serves the local population with 200 beds and approximately 13,000 annual admissions [13]. The study participants were HIV-positive women between 19-49 years of age who were sexually active in the past 6 months and not currently pregnant. Participants had to have a CD4 count $\geq 350$ cells/cc blood and be free of any AIDS-defining diseases (HIV stage I and II). Consent to the extraction of data from medical records was also required for participation. Five hundred and two eligible women were asked to participate in this study, 497 were enrolled and completed the survey (Figure 1). Twenty-one women had not disclosed their HIV status to anyone and 476 had disclosed. Of the 497 who participated, only 349 responded to our outcome question, "Who have you told about being HIV infected?" One-hundred and twenty seven observations were excluded due to not having a response to the question.

\section{Ethical approval}

This research study was approved by the Institutional Review Board at the University of Alabama at Birmingham and the Kenyatta National Hospital/University of Nairobi Ethics and Research Committee.

\section{Participant recruitment}

The clinic staff informed HIV-positive women who met the inclusion criteria about the study and asked if they were willing to participate. Women who expressed willingness to participate were then introduced to the research staff who conducted the informed consent process with the potential participants and administered a questionnaire to gather data on sociodemographic factors, social aid, stigma, social relationships, and use of Prevention of Mother-toChild-Transmission (PMTCT) services, and reproductive autonomy after receiving signed informed consent. The variables are listed in tables 1-3. Clinical information such as HIV diagnosis date, $\mathrm{CD} 4^{+}$ count, prior sexually transmitted infections (STIs), and viral load (if available) were obtained from the study participants' medical records.

\section{Statistical analysis}

The main outcome variable was the response to the question, "Who have you told about being HIV infected?" Those who disclosed to anyone other than their sexual partner (parent, child, friend, or religious leader) were merged to reflect individuals who disclosed their HIV-positive status to anyone other than a sexual partner. The sample size was calculated using the online EpiTool by Ausvet (http:// epitools.ausvet.com.au) and a 65\% HIV disclosure rate to sexual partner reported for Kenya by Farquhar C, et al [14]. The calculation estimated that 350 women were needed to assess our outcome with a $95 \%$ confidence level and 5\% margin of error; our final sample of women who responded to our outcome variable was 349 .

The sociodemographic, disclosure beliefs, health, and sexual behavior variables were categorized appropriately based on the responses to the questions on the survey and as shown in tables 1-3. For example, "Head of Household" (Self', 'Sexual partner/spouse, 'Father', 'Mother', 'Other') and for "Final say in household about health care" ('Me', 'Sexual partner/spouse,' 'Father, 'Mother', 'Other'). No response was treated as missing. There were different numbers of missing responses across questions. Missing responses were removed just for the specific variable, changing some of the questions denominators. However, the report reflects the true proportion for that variable. Basic descriptive statistics were produced for all of the variables. Chisquare was run for categorical variables. In cases where the calculated values were $<5$ Fisher's exact test was performed and t-test was run for continuous variables in order to identify differences among those who disclosed to their sexual partners versus those who disclosed to anyone other than their sexual partner. Following the bivariate analyses, a stepwise logistic regression model was conducted using the significant variables ( $p$ value $<0.05$ ) from the bivariate analysis. The logistic regression analysis was used to calculate the crude and adjusted odds of disclosure to a sexual partner compared to those who disclosed to someone other than a sexual partner using the stepwise indicated variables. Statistical analyses were performed using SAS (Statistical Analysis System, Cary, North Carolina, USA) 9.4 software, and all of the statistical tests were two-sided where $\alpha=0.05$ was considered statistically significant.

\section{Results}

Roughly, 54\% of study participants had disclosed their HIVpositive status to a religious leader, $34 \%$ to a sexual partner, $7 \%$ to a family member who was not a spouse or sexual partner, and $2 \%$ to a friend (not shown). Results from table 1 show that the majority of women (66\%) did not disclose to a sexual partner, and only $26 \%$ of those women who did not disclose were in a marital/commonlaw relationship $(p<0.0001)$. Sixty-nine percent of women who had disclosed their HIV-positive status to someone other than a sexual partner reported themselves as the head of the household, compared to $46 \%$ of women who had disclosed to a sexual partner $(\mathrm{p}<0.0001)$. Also, disclosure to a sexual partner is higher if the sexual partner or spouse serves as the head of the household when compared to disclosure to someone other than a sexual partner $(40 \%$ vs. $13 \%$; respectively; $\mathrm{p}<0.0001$ ). 
Fifty-eight percent of women who disclosed their HIV-positive status to a sexual partner and $30 \%$ of those who disclosed to someone other than a sexual partner reported having a spouse $<10$ years older than them $(\mathrm{p}<0.0001$; Table 1). Additionally, results showed that disclosure to a sexual partner is lower if the study participant reported themselves as the one who has the final say in the household about their healthcare ( $86 \% v s .69 \%$, respectively; $\mathrm{p}<0.0001)$. Among study participants, $71 \%$ of women who had disclosed their HIV-positive status to someone other than a sexual partner reported having zero pregnancies since their diagnosis, whereas only $48 \%$ of women who had disclosed to a sexual partner reported zero pregnancies $(\mathrm{p}<0.0001)$. Most participants who had disclosed their HIV-positive status to a sexual partner had two or more children alive (67\%) and accessed PMTCT services during their last pregnancy $(80 \%)$, compared to $53 \%$ and $63 \%$ of those who have disclosed their HIV-positive status to someone other than a sexual partner $(\mathrm{p}=0.0218$ and $\mathrm{p}=0.0382)$. Lastly, there is a lower proportion of disclosure to a sexual partner if the study participant had $<5$ individuals living in their household (59\% vs. 33\%, respectively; $\mathrm{p}<0.0001$ ).

Table 2 shows the difference between study participants' HIV disclosure beliefs, well-being, and sexual behaviors. There was no significant difference between those who disclosed to a sexual partner and those who disclosed to someone other than a sexual partner; the sample of those who disclosed to a sexual partner had a CD4 count of approximately $574(574.3 \pm 216.1)$ and those who disclosed to someone other than a sexual partner had a CD4 count of approximately 582 $(582.3 \pm 246.0)$. While $80 \%$ of participants who had disclosed their HIV-positive status to a sexual partner felt secure in their relationship with their partner, only $60 \%$ of participants who disclosed to someone other than a sexual partner felt secure in their relationship ( $\mathrm{p}=0.0009)$. Since their HIV diagnosis, $78 \%$ of those who had disclosed to a partner and $48 \%$ of those who disclosed to someone other than a sexual partner claim that their number of sexual partners had remained the same $(\mathrm{p}<0.0001)$. Additionally, results showed that disclosure to a sexual partner was higher if the study participant reported that the last time a condom was used stemmed from a joint decision with their partner ( $53 \%$ vs. $36 \%$, respectively; $\mathrm{p}=0.0427$ ). Disclosing one's HIV-positive status typically occurred within 24 hours after the diagnosis for both those who had disclosed to a sexual partner (78\%) and those who disclosed to someone other than a sexual partner $(60 \%, \mathrm{p}=0.0041)$. A majority of those who had disclosed to a sexual partner (65\%) and those who had disclosed to someone other than a sexual partner (45\%) disclosed their HIV-positive status because they felt it was the right thing to do $(p=0.0177)$. There is also a higher proportion of disclosure to a sexual partner among women who report that they experienced abuse in their sexual relationship as an effect of their HIV-positive disclosure ( $79 \%$ vs. $61 \%$, respectively, $\mathrm{p}=0.0252)$.

Furthermore, $88 \%$ and $86 \%$ of those who had disclosed to a sexual partner knew that there were medications to prevent MTCT of HIV during pregnancy and after birth compared to $75 \%$ of those who had disclosed to someone other than a sexual partner ( $\mathrm{p}=0.0046$ and $\mathrm{p}=0.0180$ ). Regarding accessing reproductive health services and dual contraception, $94 \%$ of women who had disclosed to someone other than a sexual partner compared to $86 \%$ of women who had disclosed to a sexual partner reported that their partner did not accompany them during their visit $(\mathrm{p}=0.0304)$ and $90 \%$ of those who had disclosed to someone other than a sexual partner compared to $81 \%$ of those who had disclosed to a sexual partner did not practice condom use and an additional method of contraception $(\mathrm{p}=0.0328)$. Results show a higher proportion of women who disclosed their HIV-positive status to someone other than a sexual partner reported not using a condom since their HIV diagnosis ( $25 \%$ vs. $12 \%$, respectively; $\mathrm{p}=0.0059$ ). Additionally, $90 \%$ of women who disclosed to someone other than a sexual partner also reported believing that HIV disclosure is important for prevention and control compared to $99 \%$ of women who disclosed their HIV-positive status to a sexual partner $(\mathrm{p}=0.0010)$. Of those who had disclosed to a sexual partner, $85 \%$ knew their sexual partner's HIV status compared to $64 \%$ of those who had not disclosed ( $\mathrm{p}<0.0001)$.

The crude odds ratios and 95\% Confidence Intervals (CI) for significant variables in the bivariate analyses are presented in table 3. Stepwise regression with a 0.1 threshold was utilized to determine the variables used in the adjusted model. Adjusted crude ratios are also presented in table 3. The odds of disclosing an HIV-positive status to a main sexual partner are 11 times more likely for women who are married or in a common-law relationship $(\mathrm{OR}=11.15$, $\mathrm{CI}=6.52$ to 19.09), 3 times more likely for women with five or more individuals living in the household $(\mathrm{OR}=2.97, \mathrm{CI}=1.87$ to 4.72$)$, and 2 times more likely for women who accessed PMTCT services during their last pregnancy $(\mathrm{OR}=2.42, \mathrm{CI}=1.04$ to 5.67$)$. Feeling secure in one's relationship ( $\mathrm{OR}=2.71, \mathrm{CI}=1.48$ to 4.95$)$, the sexual partner or spouse serving as the head of household $(\mathrm{OR}=3.69, \mathrm{CI}=1.78$ to 7.64$)$, and partner have the final say in the woman's healthcare $(\mathrm{OR}=5.24$, $\mathrm{CI}=2.52$ to 10.89 ) significantly increased the odds of disclosure to a sexual partner. Women whose number of sexual partners have remained the same since their diagnosis were 4 times more likely to disclose $(\mathrm{OR}=4.22, \mathrm{CI}=2.46$ to 7.23$)$, and women who knew about taking medication to prevent MTCT of HIV during pregnancy and after birth were 2 times more likely to disclose their HIV-positive status to a sexual partner $(\mathrm{OR}=2.39, \mathrm{CI}=1.27$ to 4.53 and $\mathrm{OR}=2.0$, $\mathrm{CI}=1.10$ to 3.63 ). The odds of disclosing to a sexual partner was 3 times more likely for those who jointly decided with their sexual partner about condom use ( $\mathrm{OR}=3.20, \mathrm{CI}=1.27$ to 8.03$), 2$ times more likely for those who have their partner accompany them to access reproductive health services $(\mathrm{OR}=2.31, \mathrm{CI}=1.08$ to 4.91$)$, and 2 times more likely for those who practice condom use plus another method of contraception $(\mathrm{OR}=2.00, \mathrm{CI}=1.06$ to 3.77$)$. Furthermore, the odds of disclosure were significantly increased among women who believed that HIV disclosure is important for HIV prevention and control $(\mathrm{OR}=12.57$, $\mathrm{CI}=1.67$ to 94.52$)$ who knew of their sexual partner's HIV status $(\mathrm{OR}=3.29, \mathrm{CI}=1.76$ to 6.13$)$, and who reported using a condom $100 \%$ of the time ( $\mathrm{OR}=2.84, \mathrm{CI}=1.43$ to 5.64$)$. The odds of disclosing were $78 \%$ less likely for those who disclosed a few months after diagnosis but within a year after their diagnosis $(\mathrm{OR}=0.22 \mathrm{CI}=0.08$ to 0.60$)$.

\section{Discussion}

This study showed significant differences in sociodemographic, HIV disclosure beliefs, health, and sexual behavior factors among women living with HIV/AIDS who attended clinics at this Kenyatta National Hospital. These factors may influence participants to disclose or not disclose their HIV-positive status to a sexual partner; for instance, a majority of the women who reported being independent, not married, and having fewer persons in the household did not disclose their HIV-positive status to their sexual partners. Without social support from a significant other, women can be left to feel vulnerable to severe consequences of their HIV-positive status, which may include physical violence and abandonment [15]. Previous research among women found that despite the understood benefits of HIV-positive disclosure, the fear of disclosure and its perceived consequences outweighed the act of disclosing to a sexual partner [16]. This is especially true in lowincome settings in Africa where the risk of intimate partner violence is increased for women living with HIV $[17,18]$. This study supports that finding as a majority of those who disclosed their HIV-positive 
Table 1: Socio-demographic variables by HIV disclosure to sexual partner.

\begin{tabular}{|c|c|c|c|}
\hline Variables & $\begin{array}{c}\text { Sexual partner } \\
\mathrm{N}=119(34.3) \mathrm{N}(\%)\end{array}$ & $\begin{array}{l}\text { Other than sexual partner } \\
\qquad \mathrm{N}=230(65.7) \mathrm{N}(\%)\end{array}$ & p-value \\
\hline \multicolumn{3}{|l|}{ Age } & 0.0033 \\
\hline $19-30$ & $25(21.0)$ & $22(9.6)$ & \\
\hline $31-40$ & $65(54.6)$ & $123(53.5)$ & \\
\hline$\geq 41$ & $29(24.4)$ & $85(37.0)$ & \\
\hline \multicolumn{3}{|l|}{ Marital status } & $<0.0001$ \\
\hline Married/Common Law & $94(79.7)$ & $59(26.0)$ & \\
\hline Single/Divorced/Widow & $24(20.3)$ & $168(74.0)$ & \\
\hline \multicolumn{3}{|c|}{ Number of persons in household } & $<0.0001$ \\
\hline$<5$ & $39(32.8)$ & $136(59.13)$ & \\
\hline$\geq 5$ & $80(67.2)$ & $94(41.2)$ & \\
\hline \multicolumn{3}{|l|}{ Head of household } & $<0.0001$ \\
\hline Self & $55(46.2)$ & $158(69.3)$ & \\
\hline Sexual partner/spouse & $47(39.5)$ & $30(13.2)$ & \\
\hline Father/Mother/Other & $17(14.3)$ & $40(17.5)$ & \\
\hline \multicolumn{3}{|c|}{ How much old is your partner/spouse than you } & $<0.0001$ \\
\hline$<10$ & $68(58.1)$ & $66(29.7)$ & \\
\hline$\geq 10$ & $32(27.4)$ & $43(19.6)$ & \\
\hline Same age & $17(14.5)$ & $113(50.9)$ & \\
\hline \multicolumn{3}{|l|}{ Residential area } & 0.1371 \\
\hline Rural & $13(11.1)$ & $38(17.2)$ & \\
\hline Urban & $104(88.9)$ & $183(82.8)$ & \\
\hline \multicolumn{3}{|c|}{ Final say in household about your health care } & $<0.0001$ \\
\hline Me & $81(68.6)$ & $198(86.1)$ & \\
\hline Sexual partner/spouse & $26(22.0)$ & $12(5.2)$ & \\
\hline Father/Mother/Other & $11(9.3)$ & $20(8.7)$ & \\
\hline \multicolumn{3}{|l|}{ Number of children alive } & 0.0218 \\
\hline 0 & $10(8.5)$ & $37(16.4)$ & \\
\hline 1 & $29(24.6)$ & $70(29.9)$ & \\
\hline$\geq 2$ & $79(66.9)$ & $119(52.7)$ & \\
\hline \multicolumn{3}{|c|}{ How many pregnancies have you had since your diagnosis? } & $<0.0001$ \\
\hline 0 & $57(47.9)$ & 159 (70.9) & \\
\hline 1 & $46(38.7)$ & $55(24.6)$ & \\
\hline$\geq 2$ & $16(13.4)$ & $10(4.5)$ & \\
\hline \multicolumn{3}{|c|}{ Did you access PMTCT services during your last pregnancy? } & 0.0382 \\
\hline Yes & $49(80.3)$ & $32(62.8)$ & \\
\hline No & $12(19.7)$ & $19(37.2)$ & \\
\hline \multicolumn{3}{|l|}{ Social status } & 0.0565 \\
\hline High & $5(4.2)$ & $3(1.3)$ & \\
\hline Average & $79(67.0)$ & $137(59.8)$ & \\
\hline Low/Below poverty line & $34(28.8)$ & $89(38.9)$ & \\
\hline \multicolumn{3}{|l|}{ Education } & 0.1177 \\
\hline Primary & $23(19.3)$ & $65(28.3)$ & \\
\hline Secondary & $54(45.4)$ & $96(41.7)$ & \\
\hline Tertiary & $41(34.5)$ & $62(27.0)$ & \\
\hline None & $1(0.8)$ & $7(3.0)$ & \\
\hline \multicolumn{3}{|l|}{ Employment status } & 0.1649 \\
\hline Employed/Self-employed & $78(66.7)$ & $169(73.8)$ & \\
\hline Unemployed & $39(33.3)$ & $60(26.2)$ & \\
\hline \multicolumn{3}{|l|}{ Religion } & 0.9639 \\
\hline Christian & $116(98.3)$ & $223(98.2)$ & \\
\hline Other/Muslim/None & $2(1.7)$ & $4(1.8)$ & \\
\hline
\end{tabular}

*Numbers may not add to total number of participants due to missing responses; Bold=significant at $p<0.05$ 
Table 2: HIV disclosure beliefs and health and sexual behavior by HIV disclosure to sexual partner.

\begin{tabular}{|c|c|c|c|}
\hline Variables & $\begin{array}{c}\text { Sexual partner } \\
\mathrm{N}=119(34.3) \mathrm{N}(\%)\end{array}$ & $\begin{array}{l}\text { Other than sexual partner } \\
\qquad \mathrm{N}=230 \text { (65.7) N (\%) }\end{array}$ & p-value \\
\hline CD4 count (mean \pm standard deviation) & $574.3 \pm 216.1$ & $582.3 \pm 246.0$ & 0.7654 \\
\hline \multicolumn{3}{|c|}{ Do you feel secure in your relationship with your partner? } & 0.0009 \\
\hline Yes & $86(80.4)$ & $71(60.2)$ & \\
\hline No & $21(19.6)$ & $47(39.8)$ & \\
\hline \multicolumn{3}{|l|}{ Are you a part of a social support group? } & 0.0213 \\
\hline Yes & $13(10.9)$ & $47(20.4)$ & \\
\hline No & $106(89.1)$ & $183(79.6)$ & \\
\hline \multicolumn{3}{|c|}{ Since your HIV diagnosis, your number of sexual partners have } & $<0.0001$ \\
\hline Remained the same & $87(77.7)$ & $105(46.7)$ & \\
\hline Increased & $3(2.7)$ & $8(3.6)$ & \\
\hline Decreased & $22(19.6)$ & $112(49.8)$ & \\
\hline \multicolumn{3}{|c|}{ If you used a condom the last time you had sex, who initiated the condom use? } & 0.0427 \\
\hline I did & $16(28.6)$ & $19(52.8)$ & \\
\hline My partner & $5(8.9)$ & $4(11.1)$ & \\
\hline Joint decision & $35(62.5)$ & $13(36.1)$ & \\
\hline \multicolumn{3}{|c|}{ How soon after diagnosis did you disclose your HIV status to someone? } & 0.0041 \\
\hline$<24$ Hours & $93(78.2)$ & $123(60.0)$ & \\
\hline Days & $7(5.9)$ & $13(6.3)$ & \\
\hline Weeks & $5(4.2)$ & $13(6.3)$ & \\
\hline$\leq 12$ Months & $5(4.2)$ & $31(15.2)$ & \\
\hline$\geq 1$ Year & $9(7.5)$ & $25(12.2)$ & \\
\hline \multicolumn{3}{|c|}{ What was the main reason for disclosing your HIV status? } & 0.0177 \\
\hline You felt it was the right thing to do & $60(65.2)$ & 75 (44.7) & \\
\hline Fear & $4(4.4)$ & $12(7.1)$ & \\
\hline You were getting sick & $24(26.1)$ & $69(41.1)$ & \\
\hline You wanted access to services & $4(4.4)$ & $12(7.1)$ & \\
\hline \multicolumn{3}{|c|}{ What has been the effect of your HIV disclosure on your sexual relationship? } & 0.0252 \\
\hline Strengthened relationship & $8(8.2)$ & $15(15.5)$ & \\
\hline Resulted in separation & $13(13.2)$ & $23(23.7)$ & \\
\hline Experienced abuse & $77(78.6)$ & $59(60.8)$ & \\
\hline \multicolumn{3}{|c|}{ Do you know about taking medication to prevent transmission of HIV to your baby during pregnancy? } & 0.0046 \\
\hline Yes & $103(88.0)$ & $166(75.5)$ & \\
\hline No & $14(12.0)$ & $54(24.5)$ & \\
\hline \multicolumn{3}{|c|}{ Do you know about taking medication to prevent transmission of HIV after the birth of your baby? } & 0.018 \\
\hline Yes & $102(85.7)$ & $168(75)$ & \\
\hline No & $17(14.3)$ & $56(25)$ & \\
\hline \multicolumn{3}{|c|}{ Does your partner accompany you to access reproductive health services? } & 0.0304 \\
\hline Yes & $16(13.6)$ & $14(6.4)$ & \\
\hline No & $102(86.4)$ & $206(93.6)$ & \\
\hline
\end{tabular}




\begin{tabular}{|c|c|c|c|}
\hline \multicolumn{3}{|c|}{ Do you practice dual protection (condom use + another method of contraception? } & \multirow[t]{2}{*}{0.0328} \\
\hline Yes & $22(18.6)$ & $23(10.3)$ & \\
\hline No & $96(81.4)$ & $201(89.7)$ & \\
\hline \multicolumn{3}{|c|}{ When were you diagnosed with HIV } & 0.8057 \\
\hline$<1$ year & $10(8.4)$ & $15(6.5)$ & \\
\hline $1-5$ years & $65(54.6)$ & $121(52.6)$ & \\
\hline $6-10$ years & $34(28.6)$ & $69(30.0)$ & \\
\hline$>10$ years & $10(8.4)$ & $25(10.9)$ & \\
\hline \multicolumn{3}{|c|}{ Health care provider told me to disclose my HIV status } & 0.5624 \\
\hline Yes & $69(93.2)$ & $68(90.4)$ & \\
\hline No & $5(6.8)$ & $7(9.3)$ & \\
\hline \multicolumn{3}{|c|}{ Health care provider explained ways I could disclose my HIV status } & 0.1769 \\
\hline Yes & $40(93.0)$ & $132(85.7)$ & \\
\hline No & $3(7.0)$ & $22(14.3)$ & \\
\hline \multicolumn{3}{|c|}{ Do you believe HIV disclosure is important for HIV prevention and control } & 0.0010 \\
\hline Yes & $112(99.1)$ & $196(89.9)$ & \\
\hline No & $1(0.9)$ & $22(10.1)$ & \\
\hline \multicolumn{3}{|c|}{ Do you think the benefit of HIV disclosure outweigh the risk } & 0.4211 \\
\hline Yes & $88(79.3)$ & $165(75.1)$ & \\
\hline No & $23(20.7)$ & $54(24.9)$ & \\
\hline \multicolumn{3}{|c|}{ Did you use a condom the last time you had sex } & 0.0891 \\
\hline Yes & $92(83.6)$ & $134(75.2)$ & \\
\hline No & $18(16.4)$ & $44(24.7)$ & \\
\hline \multicolumn{3}{|c|}{ Frequency of condom use since diagnosis } & 0.0059 \\
\hline Do not use condom & $13(11.8)$ & $45(25.4)$ & \\
\hline Use condom some/most times & $20(18.2)$ & $38(21.5)$ & \\
\hline Use condom $100 \%$ of the time & $77(70.0)$ & $94(53.1)$ & \\
\hline \multicolumn{3}{|c|}{ Do you know the HIV status of your partner } & $<0.0001$ \\
\hline Yes & $92(85.2)$ & $98(63.6)$ & \\
\hline No & $16(14.8)$ & $56(36.4)$ & \\
\hline
\end{tabular}

* Numbers may not add to total number of participants due to missing responses; Bold=significant at $p<0.05$

status to a sexual partner were found to experience abuse as a result of disclosing. Therefore, in order to increase rates of HIV-positive disclosure among women living with HIV/AIDS, interventions that provide healthcare to HIV-positive women should include routine screening and intervention for domestic violence [19].

Conserve DF, et al. found that individuals who decided to disclose their status to a sexual partner were more likely to do so because of the risk of HIV transmission and the encouragement of their sexual partner to test for HIV [16]. This study found similar results as participants who knew their sexual partner's HIV status were more likely to disclose their own HIV-positive status. Despite the fact that all participants in the study reported being sexually active, participants who had not disclosed may not have been in a stable or committed relationship. Participants who were married or in a common-law relationship were more likely to disclose their HIV-positive status to their sexual partner. Previous studies have shown similar results regarding married individuals or those living under common-law being more likely to disclose their HIV-positive status to sexual partners [20,21]. Marital/common-law status could impact disclosure as unmarried individuals often report negative reactions to disclosure that provoke violence and discrimination from their sexual partners [22]. This is consistent with our results that show women who felt more secure in their relationship were more likely to disclose their HIV-positive status to their sexual partner. Despite this finding, it is crucial for PLWHA to disclose to those with whom they engage in a sexual relationship in order to create safer relationships and prevent the transmission of HIV. Health care professionals should focus on educating individuals who have not disclosed their HIV-positive status to their sexual partners by demonstrating the importance of such disclosure. 
Table 3: Odds of disclosure of HIV status to their main sexual partner among women who are HIV-positive.

\begin{tabular}{|c|c|c|}
\hline Variables & Crude OR (95\% CI) & Adjusted OR (95\% Cl) \\
\hline \multicolumn{3}{|l|}{ Age } \\
\hline $19-30$ & Ref & \\
\hline $31-40$ & $0.47(0.24$ to 0.89$)$ & \\
\hline$\geq 41$ & $0.30(0.15$ to 0.61$)$ & \\
\hline \multicolumn{3}{|l|}{ Number of persons in household } \\
\hline$<5$ & Ref & \\
\hline$\geq 5$ & 2.97 (1.87 to 4.72$)$ & \\
\hline \multicolumn{3}{|l|}{ Marital status } \\
\hline Married/Common Law & 11.15 (6.52 to 19.09$)$ & \\
\hline Single/Divorced/Widow & Ref & \\
\hline \multicolumn{3}{|l|}{ Number of children alive } \\
\hline 0 & $0.64(0.28$ to 1.44$)$ & $0.615(0.26$ to 1.43$)$ \\
\hline 1 & Ref & Ref \\
\hline$\geq 2$ & 1.59 (0.95 to 2.67$)$ & 1.50 (0.88 to 2.58$)$ \\
\hline \multicolumn{3}{|c|}{ Did you access PMTCT services during your last pregnancy? } \\
\hline Yes & 2.42 (1.04 to 5.67$)$ & \\
\hline No & Ref & \\
\hline \multicolumn{3}{|c|}{ How much old is your partner/spouse than you? } \\
\hline$<10$ & $1.38(0.78$ to 2.45$)$ & \\
\hline$\geq 10$ & Ref & \\
\hline Same age & $0.20(0.10$ to 0.40$)$ & \\
\hline \multicolumn{3}{|c|}{ Final say in household about your health care } \\
\hline Sexual partner/spouse & $5.24(2.52$ to 10.89$)$ & \\
\hline Parents & $0.92(0.24$ to 3.54$)$ & \\
\hline $\mathrm{Me}$ & Ref & \\
\hline \multicolumn{3}{|l|}{ Head of household } \\
\hline Self & $0.82(0.43$ to 1.56$)$ & \\
\hline Sexual partner/spouse & 3.69 (1.78 to 7.64$)$ & \\
\hline Father/Mother/Other & Ref & \\
\hline \multicolumn{3}{|c|}{ Do you feel secure in your relationship with your partner? } \\
\hline Yes & 2.71 (1.48 to 4.95$)$ & \\
\hline No & Ref & \\
\hline \multicolumn{3}{|l|}{ Are you a part of a social support group? } \\
\hline Yes & $0.48(0.25$ to 0.92$)$ & \\
\hline No & Ref & \\
\hline \multicolumn{3}{|c|}{ Since your HIV diagnosis, your number of sexual partners have } \\
\hline Remained the same & $4.22(2.46$ to 7.23$)$ & \\
\hline Increased & $1.91(0.47$ to 7.77$)$ & \\
\hline Decreased & Ref & \\
\hline \multicolumn{3}{|c|}{ Do you know about taking medication to prevent transmission of HIV to your baby during pregnancy? } \\
\hline Yes & 2.39 (1.27 to 4.53$)$ & \\
\hline No & Ref & \\
\hline \multicolumn{3}{|c|}{ Do you know about taking medication to prevent transmission of HIV after the birth of your baby? } \\
\hline Yes & $2.00(1.10$ to 3.63$)$ & \\
\hline No & Ref & \\
\hline \multicolumn{3}{|c|}{ If you used a condom the last time you had sex, who initiated the condom use? } \\
\hline I did & Ref & \\
\hline My partner & $1.48(0.34$ to 6.48$)$ & \\
\hline Joint decision & 3.20 (1.27 to 8.03$)$ & \\
\hline \multicolumn{3}{|c|}{ How soon after diagnosis did you disclose your HIV status to someone? } \\
\hline$<24$ Hours & Ref & Ref \\
\hline Days & $0.71(0.27$ to 1.86$)$ & $0.69(0.26$ to 1.82$)$ \\
\hline Weeks & $0.51(0.18$ to 1.48$)$ & $0.55(0.19$ to 1.62$)$ \\
\hline$\leq 12$ Months & $0.21(0.08$ to 0.57$)$ & $0.22(0.08$ to 0.60$)$ \\
\hline$\geq 1$ Year & $0.48(0.21$ to 1.07$)$ & $0.50(0.22$ to 1.13$)$ \\
\hline \multicolumn{3}{|c|}{ Does your partner accompany you to access reproductive health services? } \\
\hline Yes & 2.31 (1.08 to 4.91$)$ & \\
\hline No & Ref & \\
\hline \multicolumn{3}{|c|}{ Do you practice dual protection (condom use+another method of contraception? } \\
\hline Yes & 2.00 (1.06 to 3.77$)$ & \\
\hline No & Ref & \\
\hline
\end{tabular}




\begin{tabular}{|c|c|c|}
\hline \multicolumn{3}{|c|}{ Do you believe HIV disclosure is important for HIV prevention and control } \\
\hline Yes & 12.57 (1.67 to 94.52$)$ & \\
\hline No & Ref & \\
\hline \multicolumn{3}{|l|}{ Knowledge of HIV status of sexual partner } \\
\hline Yes & 3.29 (1.76 to 6.13$)$ & \\
\hline No & Ref & \\
\hline \multicolumn{3}{|l|}{ Frequency of condom use since diagnosis } \\
\hline Do not use condom & Ref & \\
\hline Use condom some/most times or $100 \%$ of time & $1.82(0.80$ to 4.14$)$ & \\
\hline Use condom $100 \%$ of the time & $2.84(1.43$ to 5.64$)$ & \\
\hline
\end{tabular}

*Bold=significant at $\mathrm{p}<0.05$

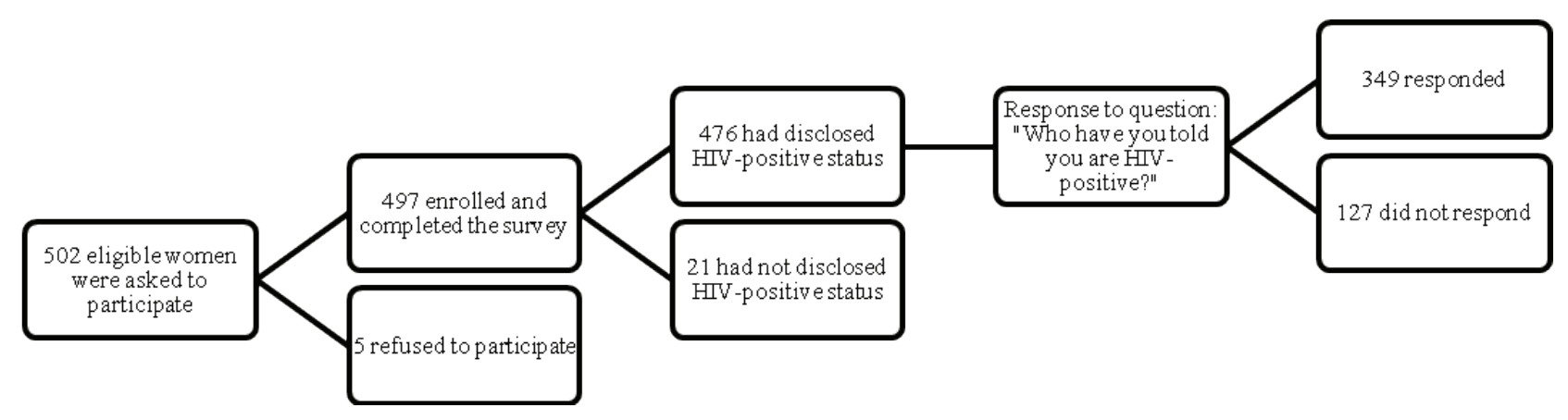

Figure 1: Flowchart showing recruitment of participants.

Women who do not disclose their HIV-positive status to their sexual partners often engage in risky sexual practices such as inconsistent condom use [23]. Results from this study are concurrent with this evidence that participants who reported using a condom $100 \%$ of the time were more likely to have disclosed their HIV-positive status to a sexual partner. Bachanas $\mathrm{P}$, et al. reported information consistent with the finding that individuals who disclosed their HIV-positive status were more likely to report using condoms consistently than those who had not disclosed [24]. The study shows that of the women who did not disclose to their sexual partners, a majority remained sexually active in addition to inconsistently using condoms, thereby increasing the risk for HIV. These women should disclose their HIV-positive status to their sexual partners, and if they do not want to disclose because of fear associated with the adverse effects on the relationship, interventions should be implemented to increase safe sexual practices during sexual encounters.

Since the study recruited participants from two high-level care hospitals in Kenya, a limitation of this study is limited generalizability of the sample that may not accurately indicate the prevalence of disclosure from women in rural settings, smaller clinics, or among those who do not seek treatment. Evidence shows that forced disclosure of HIV-positive status occurs at health care facilities due to being recognizable in health-care settings, while significant differences occur in disclosure practices between urban and rural settings [25]. Also, a primary limitation of the cross-sectional study design is the difficulty of establishing a temporal relationship between a response and an outcome; therefore, only an association can be inferred. Because a large number of predictors were included in the logistic regression model, a limitation could be the inclusion of too many predictor variables in the model caused by multicollinearity. Another limitation is that confirmation was not available when participants self-reported if they disclosed their HIV status to a sexual partner. Future research should focus on recruiting patients outside of hospital settings to attain accurate disclosure status prevalence throughout urban and rural areas of Kenya.

\section{Conclusion}

HIV disclosure is important to prevent or reduce the risk of HIV transmission. An overall low prevalence of HIV-positive disclosure to a sexual partner and high prevalence of HIV-positive disclosure to someone other than a sexual partner among women living with HIV/AIDS in Kenyan hospital settings can be noted in this study. This study shows that women who are more socially independent are less likely to disclose, and those who have not disclosed to their sexual partner engage in risky sexual behaviors. These findings may help to create interventions that target factors associated with non-disclosure to sexual partners and lead to decrease in HIV transmission. Interventions should be focused on increasing the chances of disclosure to a sexual partner by educating individuals as to why HIV disclosure is important for HIV prevention and control. The importance of HIV disclosure regardless of marital status and independence concerning household and health care decisions should be emphasized to HIV-positive individuals. Targeting individuals who have not disclosed their HIV status to a sexual partner should be the primary focus for increasing HIV disclosure. Programs should additionally develop personalized, cost-effective interventions that focus on addressing such characteristics as risky sexual behaviors that demonstrate the importance of disclosure to those with whom they engage in a sexual relationship. Nevertheless, to make conclusions as to why some individuals have not disclosed their HIV status, further studies should be conducted among individuals in and out of hospital settings and within rural and urban populations. 


\section{Acknowledgements}

We thank the women who participated in this study. We also thank the Head Nurse Mrs. Phyllis Kisabei and the other staff at Kenyatta National Hospital and Mbagathi District Hospital who helped to facilitate this study. The study was supported by the Minority Health International Research Training (MHIRT) grant no. T37-MD001448 from the National Institute on Minority Health and Health Disparities, National Institutes of Health (NIH), Bethesda, Maryland, USA and the Kenyatta National Hospital.

\section{Declaration of Competing Interests}

The authors declare that they have no competing interests.

\section{References}

1. Greeff M, Phetlhu R, Makoae L, Dlamini PS, Holzemer WL, et al. (2008) Disclosure of HIV status: Experiences and perceptions living with HIV/AIDS and nurses involved in their care in Africa. Qual Health Res 18: 311-324.

2. Varga CA, Sherman GG, Jones SA (2006) HIV-disclosure in the context of vertical transmission: HIV-positive mothers in Johannesburg, South Africa. AIDS Care 18: 952-960.

3. Medley A, Garcia-Moreno C, McGill S, Maman S (2004) Rates, barriers and outcomes of HIV serostatus disclosure among women in developing countries: implications for prevention of mother-tochild transmission programmes. Bull World Health Organ 82: 299-307.

4. Ramlagan S, Matseke G, Rodriguez VJ, Jones DL, Peltzer K, et al. (2018) Determinants of disclosure and non-disclosure of HIVpositive status, by pregnant women in rural South Africa. SAHARA J 15: 155-163.

5. Yaya I, Saka B, Landoh DE, Patchali PM, Patassi AA, et al. (2015) HIV status disclosure to sexual partners, among people living with HIV and AIDS on antiretroviral therapy at Sokodé regional hospital, Togo. PLoS One 10: e0118157.

6. Whembolua GL, Conserve DF, Thomas K, Tshiswaka DI, Handler L (2019) HIV serostatus disclosure in the Democratic Republic of the Congo: a systematic review. AIDS Care 31: 489-493.

7. King R, Katuntu D, Lifshay J, Packel L, Batamwita R, et al. (2008) Processes and outcomes of HIV serostatus disclosure to sexual partners among people living with HIV in Uganda. AIDS Behav 12: 232-243.

8. Simbayi LC, Kalichman SC, Strebel A, Cloete A, Henda N, et al. (2007) Disclosure of HIV status to sex partners and sexual risk behaviours among HIV-positive men and women, Cape Town, South Africa. Sex Transm Infect 83: 29-34.

9. World Health Organization (2004) Gender dimensions of HIV status disclosure to sexual partners: Rates, barriers and outcomes. Geneva, Switzerland.

10. Miller NA, Rubin DL (2007) Factors leading to self-disclosure of a positive HIV diagnosis in Nairobi, Kenya: People living with HIV/AIDS in the sub Sahara. Qual Health Res 17: 586-598.
11. AVERT (2018) HIV and AIDS in Kenya. Kenya.

12. National AIDS Control Council (2018) Kenya HIV estimates: Report 2018. Ministry of Health, National AIDS Control Council.

13. Ndegwa LK, Katz MA, McCormick K, Nganga Z, Mungai A, et al. (2014) Surveillance for respiratory health care-associated infections among inpatients in 3 Kenyan hospitals, 2010-2012. Am J Infect Control 42: 985-990.

14. Farquhar C, Ngacha D, Bosire R, Nduati R, Kreiss J, et al. (2000) Prevalence and correlates of partner notification regarding HIV1 in an antenatal setting in Nairobi, Kenya. XIII International AIDS Conference, Durban, South Africa.

15. Joint United Nations Programme on HIV/AIDS (2000) Opening up the HIV/AIDS epidemic. UNAIDS, WHO.

16. Conserve DF, Groves AK, Maman S (2015) Effectiveness of interventions promoting HIV serostatus disclosure to sexual partners: a systematic review. AIDS behav 19: 1763-1772.

17. Campbell JC, Baty ML, Ghandour RM, Stockman JK, Francisco L, et al. (2008) The intersection of intimate partner violence against women and HIV/AIDS: A review. Int J Inj Contr Saf Promot 15: 221-231.

18. Kouyoumdjian FG, Calzavara LM, Bondy SJ, O'Campo P, Serwadda $D$, et al. (2013) Intimate partner violence is associated with incident HIV infection in women in Uganda. AIDS 27: 1331-1338.

19. Shamu S, Zarowsky C, Shefer T, Temmerman M, Abrahams N (2014) Intimate partner violence after disclosure of HIV test results among pregnant women in Harare, Zimbabwe. PLoS One 9: e109447.

20. Gultie T, Genet M, Sebsibie G (2015) Disclosure of HIV-positive status to sexual partner and associated factors among ART users in Mekelle Hospital. HIV/AIDS (Auckl) 7: 209-214.

21. Taye G, Dereje H, Endrias M (2010) HIV positive status disclosure to sexual partner among women attending ART clinic at Awassa University Referral Hospital, SNNPR, Ethiopia. Ethiop J Health Dev 24: 9-14.

22. Ogoina D, Ikuabe P, Ebuenyi I, Harry T, Inatimi O, et al. (2015) Types and predictors of partner reactions to HIV status disclosure among HIV-infected adult Nigerians in a tertiary hospital in the Niger Delta. Afr Health Sci 15: 10-18.

23. Nduka I, Enwereji EE, Nduka EC, Ahuizi ER (2014) Determinants of Consistent Condom Use among HIV-Positive Women in Abia State, South-East Nigeria. Clinical Research in HIV AIDS and Prevention 2: 1-12.

24. Bachanas P, Medley A, Pals S, Kidder D, Antelman G, et al. (2013) Disclosure, knowledge of partner status, and condom use among HIV-positive patients attending clinical care in Tanzania, Kenya, and Namibia. AIDS Patient care STDs 27: 425-435.

25. Heleen French, Minrie Greeff, Martha J Watson, Colleen M Doak (2015) HIV stigma and disclosure experiences of people living with HIV in an urban and a rural setting. AIDS Care 27: 1042-1046. 